\title{
Cost-Savings and Patient Experience with a Pharmacy-Led Medicare Part D Consultation Service
}

Logan Murry, PharmD ${ }^{1}$; Brandon Gerleman, PharmD ${ }^{2}$; Huiwen Deng, PharmD ${ }^{3}$; Julie Urmie, $P h D^{1}$

${ }^{1}$ Department of Pharmacy Practice and Science, The University of lowa College of Pharmacy, lowa City, IA

${ }^{2}$ OutcomesMTM, Des Moines, IA; ${ }^{3}$ Department of Pharmacy Practice, Policy and Outcomes, The University of Illinois-Chicago

\begin{abstract}
Background: There are many Medicare Part D plans, making it difficult for patients to choose the optimal plan. The decision to remain on current Medicare plans is reinforced by patient inertia and uncertainty associated with plan-switching decisions. By helping patients identify more cost-effective plans, pharmacists and pharmacy personnel have the ability to inform plan-switching decisions resulting in lower out-of-pocket (OOP) costs.

Objectives: This study evaluates 1) patient experience with a pharmacy Medicare Part D consultation service and 2) potential out-ofpocket savings based on a patient's best plan for 2019 compared to continuation of a patient's 2018 Medicare Part D plan.

Methods: This study was a retrospective descriptive analysis and took place at a single, independently owned community pharmacy. Patients received free individual consultations with a pharmacist that included a medication review and information on all available Part D plans. Patients were selected to receive the service using pharmacy software to identify potential inefficiencies in current Part $D$ plans. Data on satisfaction and perceived pharmacist role in providing Medicare Part D information were collected via an in-person survey administered at the pharmacy. Potential out-of-pocket cost savings were determined using cost information provided for patient specific medication regimens entered into Medicare.gov, the online platform for Medicare Part D plan information.

Results: Of the 318 patients identified, 79 used the consultation service. Out of 79 patients who used the service in fall of 2017, 44 completed the survey for a response rate of $56 \%$.

Patients generally reported good experiences with the service. Open-ended responses revealed patients utilize a variety of helpers for plan information and decisions. A subset of 14 patients were identified as having clear plan-switching decisions and were included in the cost-savings analysis.

Conclusions: Patients using a free Medicare Part D plan consultation were satisfied with the service, suggesting that helpers were an important resource $n$ their plan-selection process. Using the pharmacist-led Part D consultation may result in decreases in out-of-pocket cost savings due to identification of optimal Medicare Part D plans.
\end{abstract}

Keywords: pharmacy practice, Medicare Part D, pharmacy service, satisfaction, cost-savings

\section{Introduction}

In the Medicare Part D population, beneficiaries typically overspend on medication costs and premiums affiliated with their annual Medicare Part D plan. ${ }^{1}$ Overspending may be due to selecting plans with higher out-of-pocket (OOP) costs than necessary based on a patient's current medication regimen, with beneficiaries required to choose from a large number of plans with confusing benefit designs. ${ }^{1,2,3}$ Most recently, lowercost plans were identified for $61 \%$ of a Medicare Part $D$ population $(n=1068)$, with a median cost savings of $\$ 538$ USD per patient. ${ }^{2}$

Although beneficiaries are subject to overspending and year-toyear changes in benefit design, many do not choose to annually re-evaluate plan options. ${ }^{1-4}$ The rate of plan switching for an lowa Medicare population in 2012-2013 was $17.8 \%{ }^{3}$ Nationally, only $10 \%$ of Medicare-eligible patients switched plans from 2016 to $2017 . .^{5}$ The decision to remain on current

Corresponding author: Logan T Murry, PharmD

The University of lowa College of Pharmacy

180 S. Grand Avenue, 333 CPB

lowa City, IA 52242

Phone: 319-325-9055; Email: logan-murry@uiowa.edu
Medicare plans is reinforced by patient inertia and uncertainty associated with plan-switching decisions. ${ }^{3}$ Medicare beneficiaries who switch plans are twice as likely to have received help in reviewing coverage options than those patients who do not switch (90\% vs. $45.29 \%)$, suggesting helpers are important in plan-switching decisions. ${ }^{3}$ Community pharmacies currently offering Medicare Part D consultation services have the ability to help patients with their Medicare Part D plan selection, informing plan-switching decisions resulting in lower OOP costs and increased medication adherence. ${ }^{3,5,6}$

Despite the potential benefits of community pharmacy Part $D$ services, few patients consistently participate, with $15 \%$ of patients taking three or more medications reporting they using a pharmacist for Medicare Part D plan selection assistance. ${ }^{7}$ While work has been done to evaluate patient satisfaction and experience with other community pharmacy services, factors contributing to patient perceptions and experiences with Medicare Part $\mathrm{D}$ consultations offered in community pharmacy settings are not well understood. ${ }^{8-11}$ There is clear need to understand patient perceptions of the pharmacist's role in and knowledge of Medicare Part D plan selection, allowing for a greater understanding of Medicare Part D service use, value, and experience, while identifying patient benefits like costsavings opportunities. 


\section{Objectives}

The objectives of this study were to 1 ) evaluate the patient experience with a free Medicare Part $D$ consultation service offered by a community pharmacy and 2) calculate potential out-of-pocket savings based on the lowest OOP cost plan for 2019 compared to OOP costs associated with a continuation of a patient's 2018 Medicare Part D plan.

\section{Methods}

The study was granted a non-human subjects research determination and was conducted in compliance with Institutional Review Board/Human Subjects Research Committee requirements. The study was a retrospective analysis that took place at a single, independently owned community pharmacy in lowa. Using third-party software, the pharmacy identified patients who were currently enrolled in Medicare Prescription Drug Plans (PDPs) with higher OOP costs than necessary. OOP costs were considered higher than necessary when plans with comparable medication coverage were available with lower OOP costs. The third-party software of interest was previously integrated into the pharmacy dispensing and management system and was used to compare Medicare Part D plans for current pharmacy patients based on chronic medications and continued pharmacy use. The software identified patients who may be overspending on their current plan, based on premium or deductible increases. The software then identified plans with comparable medication coverage, but offered cost-savings based on decreased yearly OOP medication costs. All individuals who were identified by the third-party software received a phone call from the community pharmacy, offering them a free Medicare Part D consultation appointment. While patients identified by the third-party software were of primary interest, the service was also available and advertised to the general public through newspaper advertisements, phone calls, and in-person conversations.

The Medicare Part D consultation service included a comprehensive medication review intended to improve an eligible patient's prescription insurance plan and medication therapy. During the Medicare Part D open-enrollment period, patients scheduled an appointment with their pharmacist. During the appointment, pharmacists collected information on patient prescription medications, vitamins, herbals, and supplements. Based on current medications, the pharmacist presented plan options which were identified by the third-party software. The patient saw transparent pricing for each prescription drug plan, including when they were anticipated to reach their deductible, when they would reach the donut hole, the monthly premiums, and the patient cost-sharing for each prescription medication. Patients were then directed to computers available in the pharmacy to sign up for their Medicare Part D plan. While pharmacists assisted in identifying Part D plans, patients were responsible for selecting their preferred plan and subsequently signing up. The patient left the encounter with an updated medication list and a confirmation print out of their registration for next year's prescription drug plan. The free service varied in duration, but typically took 30 to 45 minutes.

\section{Objective 1: Patient Experience Survey}

The survey was developed by community pharmacy staff prior to researcher involvement, with our expertise used during the analysis and interpretation process. The pharmacists created survey questions they felt captured important components of the Medicare Part D consultation. These questions were divided into the following four survey sections: Pharmacy Knowledge and My Experience (7 items), Plan Switching (3 items), Use and Referral (2 items), and Additional Info and Pharmacist Role (3 items). The survey instrument developed and used by the community pharmacy is included in Appendix A, with pharmacy specific information redacted.

The survey was administered after the Medicare Part D consultation was completed in the fall of 2017 Medicare Part D open enrollment period. Immediately after the Medicare Part D consultation, the pharmacist initiated and collected survey responses. All patients who participated in the Medicare Part D consultation service were asked to complete a survey. Patients who did not use the consultation service did not participate in the survey. Survey responses were deidentified by the community pharmacy staff and mailed to the research team. Descriptive analysis was performed on survey items. Openended survey item responses were collected and reported. Formal thematic analysis was not performed on open-ended responses due to the specific nature of the questions and small number of responses.

\section{Objective 2: Potential Cost Savings}

The pharmacy provided deidentified dispensing data for all of 2017 and 2018. As this was a part of a larger analysis ${ }^{6}$, a small subset of patients was included in the cost savings calculation and had to meet a number of inclusion criteria. First, a current 2018 Medicare Part D plan needed to be clearly identifiable. This was required to compare projected total costs between a patient's current 2018 plan continued into 2019 and the 2019 plan with the lowest total OOP costs. Additionally, only chronic medications were included in the cost savings calculation to assure accurate cost savings information. Chronic medications were identified based on presence in both 2017 and 2018 dispensing data, with comparable quantity and day supply. After 2018 plans and chronic medications were identified, each patient's medications were entered into the Medicare Part D plan-finder that was available from Medicare.gov, providing total projected OOP costs based on a January $1^{\text {st }}, 2019$ coverage start date. Projected 2019 OOP costs were identified for each patient's current 2018 plan continued into 2019 and the 2019 plan with the lowest OOP costs. Projected total cost savings was calculated based on the difference in OOP costs between a patient's continued 2018 plan and the 2019 plan with the lowest OOP cost. Similar to past cost saving evaluations, median cost savings were calculated to control for potential outliers. ${ }^{2}$ 


\section{Results}

\section{Objective 1: Patient Experience and Service Experience}

For the 2018 plan year, the pharmacy identified 318 patients who could benefit from a Medicare Part D consultation to select a more appropriate plan. A total of 79 patients used the consultation service $(24.8 \%)$, although some of these patients may have used the service without formal recruitment. Of 79 patients who used the service in fall of 2017, 44 completed the survey for a response rate of $56 \%$. Overall, patients who used the pharmacy service believed pharmacists were knowledgeable about medication costs, medication changes, and were able to answer Medicare Part D questions (77.3\% Strongly Agree). A large percentage of patients who used the pharmacy service had previously switched plans (59.1\%) and $71.4 \%$ of patients who used the service reported they were "Definitely switching" Medicare Part D plans this year. The majority of patients who used the pharmacy service had been patients at the community pharmacy for more than three years (90.7\%). Patients who used the pharmacy service received assistance from a wide variety of resources in previous years, with insurance agents (37.2\%) and pharmacists (34.9\%) reported most frequently. Patients were generally pleased with the Medicare Part D consultation service, reporting a mean score of $4.75 \pm 0.066$. Table 1 and Table 2 shows responses to survey items.

Of the 44 surveys completed, 22 patients responded to at least one open-ended question. From open-ended responses, patients gathered information from a variety of sources (SHIP Agent, TV Commercials). Patient were generally pleased with the pharmacy service and were primarily concerned with a variety of benefit components associated with cost, such as premiums and medication copays. Table 3 shows representative open-ended responses to survey items.

Table 1. Survey Section 1 Question Responses: Pharmacy Knowledge and My Experience $(n=44)$

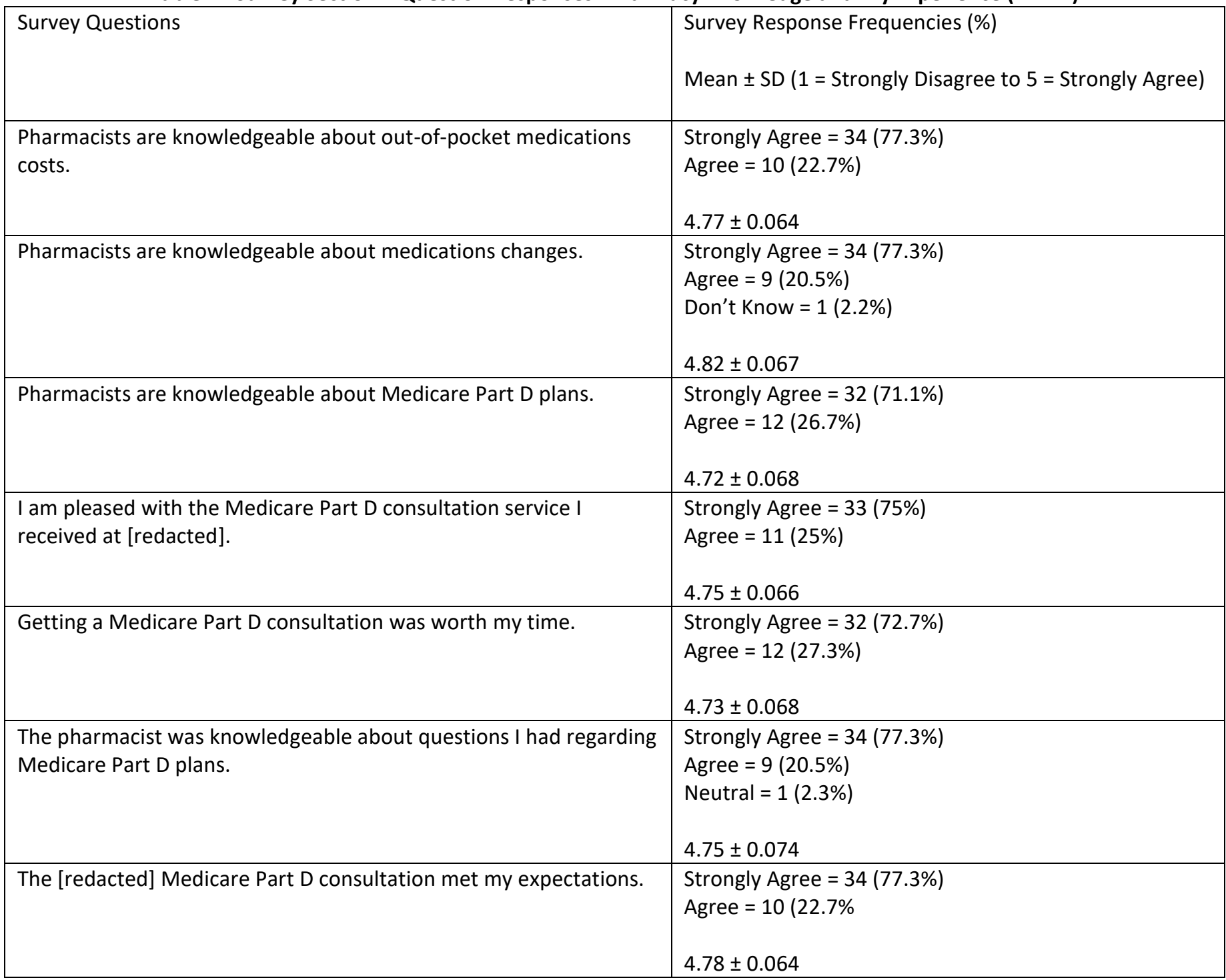


Table 2. Survey Responses: Plan Switching, Use and Referral, Additional Info and Pharmacist Role $(n=44)$

\begin{tabular}{|c|c|}
\hline Plan Switching & \\
\hline Have you ever switched Medicare Part D plans? & $\begin{array}{l}\text { Yes }=26(59.1 \%) \\
\text { No }=18(40.9 \%)\end{array}$ \\
\hline $\begin{array}{l}\text { How important was the Medicare Part D consultation } \\
\text { in your decision to switch plans? }\end{array}$ & $\begin{array}{l}\text { Very Important: } 31(70.5 \%) \\
\text { Important: } 12(27.3 \%) \\
\text { Slightly Important: } 1(2.3 \%) \\
\text { Not Important: } 0(0 \%)\end{array}$ \\
\hline For this year, what is your plan switching decision? & $\begin{array}{l}\text { Definitely switching: } 30(71.4 \%) \\
\text { Leaning toward switching: } 2(4.8 \%) \\
\text { Leaning toward not switching: } 0(0 \%) \\
\text { Definitely not switching: } 10(23.8 \%)\end{array}$ \\
\hline Use and Referral & \\
\hline $\begin{array}{l}\text { What is the likelihood of returning for your Medicare } \\
\text { Part D consultation next year at [redacted]? }\end{array}$ & $\begin{array}{l}\text { Very Likely }=38(88.4 \%) \\
\text { Likely }=3(7 \%) \\
\text { Not Likely }=0(0 \%) \\
\text { Very Unlikely }=2(4.7 \%)\end{array}$ \\
\hline $\begin{array}{l}\text { How likely would you be to recommend this service to } \\
\text { others? }\end{array}$ & $\begin{array}{l}\text { Very Likely = } 39(86.7 \%) \\
\text { Likely }=4(8.9 \%) \\
\text { Unlikely }=0(0 \%) \\
\text { Very Unlikely }=0(0 \%)\end{array}$ \\
\hline Additional Info and Pharmacist Role & \\
\hline How long have you been a patient at the pharmacy? & $\begin{array}{l}\text { I am a new patient: } 2(4.7 \%) \\
\text { Less than } 1 \text { year: } 0(0 \%) \\
\text { At least } 1 \text { year, but less than } 3 \text { years: } 2(4.7 \%) \\
\text { More than } 3 \text { years: } 40(90.7 \%)\end{array}$ \\
\hline $\begin{array}{l}\text { Who has assisted with selecting your Medicare Part D } \\
\text { in the past? }\end{array}$ & $\begin{array}{l}\text { Insurance Agent = } 16(37.2 \%) \\
\text { Pharmacist }=15(34.9 \%) \\
\text { SHIP Volunteer }=6(14 \%) \\
\text { Friend }=1(2.3 \%) \\
\text { Other }=5(11.6 \%)\end{array}$ \\
\hline $\begin{array}{l}\text { Who is most informed pertaining to your Medicare } \\
\text { Part D plan and Medicare Part D plan switching? }\end{array}$ & $\begin{array}{l}\text { Pharmacist }=41(97.6 \%) \\
\text { Other }=1(2.4 \%) \\
\text { Insurance Agent }=0(0 \%) \\
\text { SHIP Volunteer }=0(0 \%) \\
\text { Friend }=0(0 \%)\end{array}$ \\
\hline
\end{tabular}


Table 3. Open-ended Responses $(n=22)$

\begin{tabular}{l|l}
\hline Open-ended Survey Item & Selected Responses
\end{tabular}

What, if anything, have you done prior to our consultation today to discuss and compare Medicare Part D plans?

To what degree are you satisfied with our Medication Part D consultation service? Was this pharmacist consultation what you expected?

What factors were most important to you when comparing Medicare Part D plans?

Please use the rest of the page to add any constructive comments that you believe we can improve on regarding the Medicare Part D consultation service.
"None-went over all plans by self to try and figure out."

"Tried reading about it, very confusing, pharmacists are knowledgeable; SHIP guy didn't have an idea-no help at all, Pharmacist knows my medication and dosages-very helpful."

\section{"Used SHIP."}

“TV Commercials."

"Just a lot of thinking."

"Amazing! Went above and beyond. Made sure we understood every aspect of the change."

"Better than expected-didn't think it would be that easy to do/look at."

"Very satisfied savings over $\$ 10,000 . "$

"Very satisfied, more informed than agent."

"Prices of drugs. Explanation help in donut hole."

"Cost of all plans, the number of drugs covered and the cost of copays."

"Monthly premium, out of pocket expense, yearly savings."

"This service has been very helpful in helping us to choose a good plan that best fits our health issues!"

"I was very happy with service plus free coffee."

"I need the pharmacist to help and explain the difference of plans and to recommend which one would be to my benefit."

"This service has been very helpful the last 2 years." 
Objective 2: Potential Cost-savings

For the subset of 14 patients where their plan sponsor changed and clear plan- switching decisions occurred for the 2018 plan year period (e.g. they did not select a new plan offered by their current insurance provider), all patients were projected to experience savings by switching insurance providers for 2019. The total potential savings as projected by the Medicare plan- finder based upon January $1^{\text {st }}$ open enrollment period ranged from a minimum savings of $\$ 72.32$ to a maximum savings of $\$ 841.05$. Number of medications ranged from 1 to 10 , with a total savings of $\$ 4318.89$ for all 14 beneficiaries and a median savings of $\$ 248.50$. Potential-cost savings data is included in Table 4.

Table 4. Potential Savings Based on Continued 2018 vs Lowest OOP cost plan for 2019

\begin{tabular}{|l|l|l|l|l|}
\hline Pt & \# of Medications & $\begin{array}{l}\text { Continued 2018 Plan } \\
\text { Projected Costs (USD) }\end{array}$ & $\begin{array}{l}\text { Lowest OOP cost plan for } \\
\mathbf{2 0 1 9} \text { Projected Costs (USD) }\end{array}$ & $\begin{array}{l}\text { Total Potential } \\
\text { Savings (USD) }\end{array}$ \\
\hline 1 & 2 & $\$ 405.60$ & $\$ 180.00$ & $\$ 225.60$ \\
\hline 2 & 7 & $\$ 774.72$ & $\$ 330.08$ & $\$ 444.64$ \\
\hline 3 & 2 & $\$ 535.30$ & $\$ 180.00$ & $\$ 355.30$ \\
\hline 4 & 4 & $\$ 858.02$ & $\$ 475.12$ & $\$ 382.90$ \\
\hline 5 & 2 & $\$ 1267.20$ & $\$ 995.00$ & $\$ 272.20$ \\
\hline 6 & 2 & $\$ 804.80$ & $\$ 180.00$ & $\$ 624.80$ \\
\hline 7 & 9 & $\$ 2737.91$ & $\$ 1896.86$ & $\$ 841.05$ \\
\hline 8 & 1 & $\$ 387.06$ & $\$ 225.78$ & $\$ 161.28$ \\
\hline 9 & 3 & $\$ 415.02$ & $\$ 189.42$ & $\$ 225.60$ \\
\hline 10 & 2 & $\$ 339.60$ & $\$ 180.00$ & $\$ 159.60$ \\
\hline 11 & 10 & $\$ 4372.21$ & $\$ 1359.08$ & $\$ 72.32$ \\
\hline 12 & 7 & $\$ 1533.50$ & $\$ 701.76$ & $\$ 174.42$ \\
\hline 13 & 6 & $\$ 950.26$ & $\$ 1430.39$ & $\$ 248.50$ \\
\hline 14 & 11 & $\$ 1561.07$ & $\$ 4318.89(\$ 248.50)$ & $\$ 130.68$ \\
\hline Total Savings (Median Savings/Person) USD & & \\
\hline
\end{tabular}

\section{Discussion}

Based on survey responses, there was variation in the types of resources patients had historically used for Medicare Part D assistance. The largest number of respondents reported using an insurance agent as a Medicare Part D plan resource, with pharmacist reported as the second most frequent. Qualitative responses showed that individuals used SHIP Agents and TV Commercials to inform their Medicare Part D plan decision. While only $34.9 \%$ of respondents had previously used a pharmacist as a Medicare Part D resource, this was considerably higher than in a previous study, where only $15 \%$ of Medicare Part $D$ beneficiaries taking three or more medications using a pharmacy or pharmacist for Part D information. ${ }^{7}$ Using the pharmacy service generally resulted in good experiences, and patients often compared the experience with their pharmacist to other Medicare Part $D$ resources. Patients agreed that their pharmacist was knowledgeable about Medicare Part D and a potentially better resource than they had used previously.

In addition to being pleased with the pharmacy service, the majority of service users reported that the service was either very important or important to their plan switching decision (97.8\%) and $71.4 \%$ of patients who used the service reported that they were "definitely switching" plans for 2018. Based on previous evaluations of this patient population, the Medicare Part D plan switching rate for individuals who used the
Medicare Part D consultation service in 2018 was $43 \%{ }^{6}$ While the 2018 switching rate for individuals who used the service was considerably higher than those that did not $(43 \%$ for service users compared to $4 \%$ for nonusers) ${ }^{6}$, many patients who used the service still may have been uncertain about their plan-switching decision.

Cost information was consistently important to patients and often was the focal point of their plan comparison, as depicted in the open-ended survey responses. For the subset of patients where plan-switching decisions could be accurately assessed, all patients would benefit from switching plans. The potential reduction in OOP costs reported in this study are consistent with results from a comparable study using telephone Medicare Part D consultations performed by telephone in an academic institution. ${ }^{3}$ With $71.4 \%$ of patients reporting they intended to switch plans, and cost being one of the major focuses of their plan comparison, it may be inferred that a large percentage of individuals using the service realized they may experience costsavings, should they switch plans. As previously reported, only $43 \%$ of individuals who used this service actually switched plans in $2018 .^{6}$ While a large percentage of service users may have had an opportunity to decrease OOP costs, some patients chose not to switch plans. From these results, satisfaction, service importance, and potential cost-savings alone may not be enough to mobilize all patients to a plan switching decision, despite potential benefits. 
Limitations and Future Research

While we were able to identify who used the service, we were unable to link the survey responses to these patients. Additionally, as patients were recruited to receive the service based on potential Medicare Part D plan inefficiencies, selection bias may influence the potential cost savings given that these patients were on potentially inefficient plans. Medicare Advantage plans with drug coverage (MA-PDs) were excluded due to pharmacy preference in who received consultations. Given that the data was only available for a small subset of patients with clear plan switching decisions, further evaluation on realized cost savings is worth further exploration. Social desirability bias may be present, as many participants were long-time pharmacy customers and completed the survey at the community pharmacy of interest. This likely influenced patient experiences with the service. Lastly, the results are likely not generalizable due to small sample size and the inclusion of patients from one community pharmacy. Additional work should be done to evaluate the effect of the recent change to the Medicare Part D plan selection website. As the website underwent a recent overhaul, there may be a considerable impact on patient access, plan information attainment, and overall effect on the Medicare Part D population.

While this particular pharmacy was able to implement the service into workflow and provide the service at no charge, additional opportunities for reimbursement and service expansion should be considered to make the service sustainable in a myriad of practice settings. Future research should focus on patients who use Medicare Part D consultation services, but choose not to switch plans in spite of the potential for cost-savings. Further evaluation should be performed to identify additional influences on patient plan-switching behavior.

\section{Conclusion}

Overall, patients were pleased with the pharmacy Part D consultation service and there may be considerable opportunity for beneficiary cost-savings as a result of switching Part D plans. Pharmacists and pharmacies may be well positioned to assist patients with Medicare Part plan selection.

Acknowledgments: The authors would like to thank the pharmacists for providing the service

\section{Conflicts of Interest: None}

Funding/Support: None
References

1. Zhou C, Zhang Y. The vast majority of Medicare Part D beneficiaries still don't choose the cheapest plans that meet their medication needs. Health affairs (Project Hope). 2012;31(10):2259-2265.

2. Massey $C$, Aungst TD, Evans $P$, Bartlett $D$, Silva MA. Cost savings impact of a pharmacist-initiated teleservice program for Medicare Part D reviews. Journal of the American Pharmacists Association. 2018;58(1):56-60.

3. Cubanski JD HJ, Orgera K, Neuman T. Medicare Part D: A First Look at Prescription Drug Plans in 2018 Online The Henry J. Kasier Family Foundation 2017.

4. Han J, Urmie J. Medicare Part D Beneficiaries' Plan Switching Decisions and Information Processing. Medical Care Research and Review. 2018;75(6):721745.

5. Koma W, Cubanski J, Jacobson G, et al. No itch to switch: few Medicare beneficiaries switch plans during the open enrollment period. Kaiser Family Foundation. 2019. https://www.kff.org/ reportsection/no-itch-to-switch-few-medicarebeneficiaries- switch-plans-during-the-openenrollment-period-methods/. Accessed December 9, 2019.

6. Murry LT, Murry RC, Gerleman B, Deng H, Viyyuri B, Urmie J. Community pharmacy Medicare Part D consultations: plan switching decisions and chronic medication adherence. Journal of Pharmacy Practice. In Press.

7. Kennelty KA, Thorpe JM, Chewning B, Mott DA. Use of pharmacists or pharmacies as Medicare Part $D$ information sources. Journal of the American Pharmacists Association : JAPhA. 2012;52(6):e205209.

8. Ayalew MB, Taye K, Asfaw D, et al. Patients'/Clients' Expectation Toward and Satisfaction from Pharmacy Services. Journal of Research in Pharmacy Practice. 2017;6(1):21-26. doi:10.4103/2279-042X.200995

9. Farris, K. B., Stenton, S. B., Samnani, M., \& Samycia, D. (2000). How satisfied are your patients?. Canadian Pharmacists Journal, 133(8), 32.

10. Kucukarslan, Suzan, and Jon C. Schommer. "Patients' expectations and their satisfaction with pharmacy services." Journal of the American Pharmaceutical Association (1996)42.3 (2002): 489-496.

11. Stults CD, Fattahi S, Meehan A, et al. Comparative Usability Study of a Newly Created Patient-Centered Tool and Medicare.gov Plan Finder to Help Medicare Beneficiaries Choose Prescription Drug Plans. Journal of Patient Experience. 2019;6(1):81-86. doi:10.1177/2374373518778343 


\section{Appendix A.}

This survey is intended for patients to give their feedback and opinion regarding their experience with [redacted]. Your results will remain anonymous and confidential. Thank you in advance for taking your valuable time to help us better serve you.

Please circle your level of agreement with each statement using the scale provided.

\section{Section 1: Pharmacy Knowledge and My Experience}

For the following items, please recall your recent visit to Montross Pharmacy involving your Medicare Part D Consultation. Please mark your agreement or disagreement with the following statements and return your responses in the accompanying pre-stamped envelope or drop it off at your most convenient time to the pharmacy.

Strongly
Disagree Disagree Neutral Agree Agree Know't

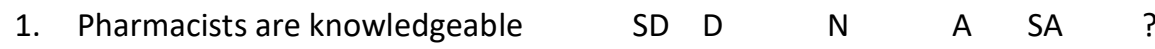
about out-of-pocket medication costs.

2. Pharmacists are knowledgeable about

\begin{tabular}{|c|c|c|c|c|c|c|}
\hline SD & D & $\mathrm{N}$ & $A$ & SA & ? & medication changes. \\
\hline & D & $\mathrm{N}$ & A & & & \\
\hline
\end{tabular}

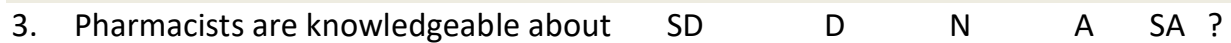
Medicare Part D plans.

4. I am pleased with the Medicare Part D $\quad$ SD $\quad$ D $\quad N \quad$ A $\quad$ SA ? consultation service I received at

[redacted] Pharmacy.

5. Getting a Medicare Part D consultation SD $\quad$ D $\quad N \quad$ A SA ? was worth my time.

6. The pharmacist was knowledgeable About questions I had regarding SD $\quad D \quad N \quad$ A $\quad$ SA ? Medicare Part D plans.

7. The [redacted] Medicare Part D SD D N A SA my expectations.

\section{Section 2. Plan Switching}

1. Have you ever switched Medicare Part D plans?

Yes

No

2. How important was your [redacted] Medicare Part D consultation in your decision to switch plans?

Not important [ ]

Slightly Important [ ]

Important [ ]

Very Important [ ]

4. For this year, what is your plan switching decision?

Not Switching [ ]

Leaning toward not switching [ ]

Leaning toward switching [ ]

Definitely Switching [ ] 


\section{Part 3: Use and Referral}

1. What is your likelihood of returning for you Medicare Part D consultation next year at Montross Pharmacy?

Very Unlikely [ ]

Not Likely [ ]

Likely [ ]

Very Likely [ ]

2. How likely would you be to recommend this service to others?

Very Unlikely [ ]

Not Likely [ ]

Likely [ ]

Very Likely [ ]

\section{Part 4: Additional Info and Pharmacist Role}

1. How long have you been a patient at Montross Pharmacy?

[ ] I am a new patient

[ ] Less than 1 year

[ ] At least 1 year, but less than 3 years

[ ] More than 3 years

2. Who has assisted with selecting your Medicare Part D in the past?

[ ] Insurance agent

[ ] SHIP (State Health Insurance Assistance Program) volunteer

[ ] Pharmacist

[ ] Friend

[ ] Other

3. Who is most informed pertaining to your Medicare Part D plan and Medicare Part D plan switching?

[ ] Insurance agent

[ ] SHIP (State Health Insurance Assistance Program) volunteer

[ ] Pharmacist

[ ] Friend

[ ] Other :

Section 5: Free Response

1. What, if anything, have you done prior to our consultation today to discuss and compare Medicare Part D plans? 
2. To what degree are you satisfied with our Medication Part D consultation service? Was this pharmacist consultation what you expected?

3. What factors were most important to you when comparing Medicare Part D plans?

4. Please use the rest of the page to add any constructive comments that you believe we can improve on regarding the Medicare Part D consultation service.

Thank you for helping us better serve you! $\odot$ 